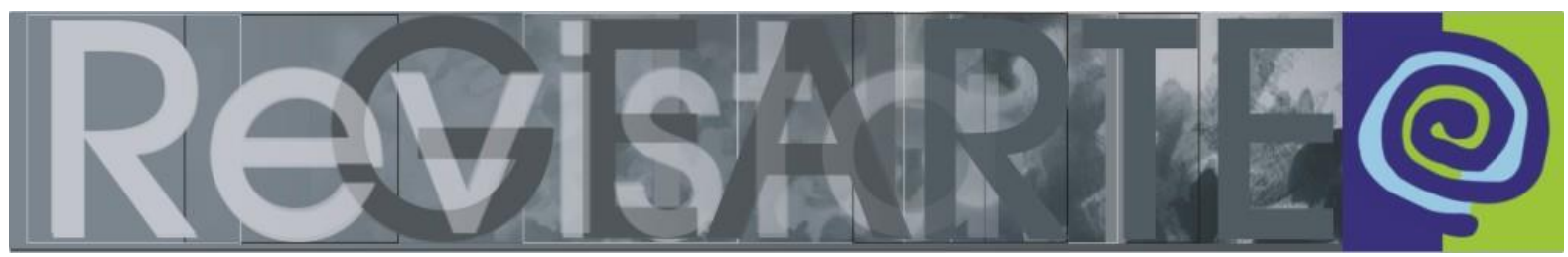

e-ISSN 2357-9854

\title{
Abordagem Triangular em Diálogo com o Tempo: pegadas no passado, passos para o futuro
}

\author{
Fernanda Pereira da Cunha (Universidade Federal \\ de Goiás - UFG, Goiânia/ GO, Brasil)
}

\begin{abstract}
RESUMO - Abordagem Triangular em Diálogo com o Tempo: pegadas no passado, passos para o futuro - Este texto busca refletir sobre aspectos da tecnocultura que balizam na contemporaneidade a necessidade da promoção do desenvolvimento da consciência crítica de um novo estado da mente humana: a mente digital. Com o advento das tecnologias digitais, estabeleceram-se,outras formas de interações comunicacionais ascendendo à cultura digital, com práticas e costumes peculiares da cibercultura no cotidiano das pessoas que integram os diferentes discursos bem como a interconexão entre som, imagem e texto, ou seja, o advento da metalinguagem. Coloca-se, neste âmbito da tecnologia conceitual, que estabelece um novo estado da mente humana, a necessidade de ações earte/educativas em prol do desenvolvimento da mente digital autogovernativa através da artecibercultural e seu ensino. Esta perspectiva se ancora numa abordagem arte/educativa digital intitulada Sistema Triangular Digital, cujo sistema advém da derivação da Abordagem Triangular concebida e sistematizada por Ana Mae Barbosa.
\end{abstract}

PALAVRAS-CHAVE

e-Arte/Educação. Mente digital crítica. Metalinguagem. Ciberespaço.

ABSTRACT - Triangular Approach in dialogue with time: footsteps in the past, steps to the future - This text seeks to reflect on aspects of technoculture that mark the contemporary need to promote the development of critical awareness of a new state of the human mind: the digital mind. With the advent of digital technologies, other forms of communicational interactions were established succeeding to the digital culture, with peculiar practices and customs of cyberculture in the daily lives of the people that integrate the different discourses, as well as the interconnection between sound, image and text, that is, the advent of metalanguage. In this context of conceptual technology, that creates a new state of the human mind, the need for e-art/educational actions in favor of the development of the digital self-governing mind through cultural and cultural education. This perspective is anchored in a digital art/ education approach, the Digital Triangular System, whose system comes from the derivation of the Triangular Approach conceived and systematized by Ana Mae Barbosa.

KEYWORDS

e-Art/Education. Critical digital mind. Metalanguage. Cyberspace.

CUNHA, Fernanda Pereira da. Abordagem Triangular em Diálogo 


\section{Abordagem Triangular em consonância com a contemporaneidade digital}

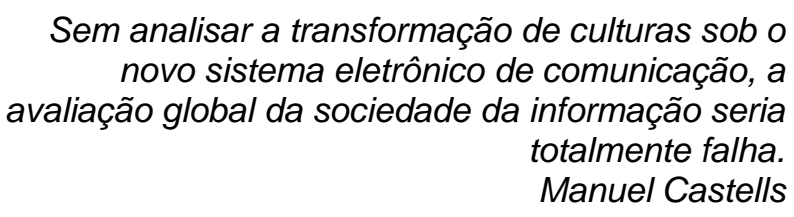

Na busca determinada de uma abordagem arte/educativa pós-colonialista, a professora Ana Mae Barbosa, conectada com as vozes do mundo, pela sua natureza indócil, crítica, de educadora, sempre cultivou a pesquisa como meio de reflexão para sua análise, seja no plano da vida pessoal como da vida profissional, na qual mantém diálogo investigativo com abordagens educativas do ensino das artes no cenário internacional. É neste ambiente investigativo, de olhar brasileiro em relação internacional, que se situa a Abordagem Triangular pós-colonialista, um ícone arte/educativo na contemporaneidade.

A Abordagem Triangular, por ser uma perspectiva cuja gênese epistemológica se alicerça em seu caráter genuinamente contextual, é uma abordagem em processo, portanto, contínua, dado seu aspecto orgânico, voltando-se para o desenvolvimento da identidade cultural e da cognição/percepção.

Assim, a sistematização da Abordagem Triangular acontece no tempo gramatical do gerúndio, porque dialoga no curso do e com o tempo. Neste sentido, a força motriz desta Abordagem, de natureza conceitual cultural e dialogal, torna-a flexível e contemporânea no curso do tempo. A Abordagem Triangular perfaz uma rede sistêmica, por isso, viva, orgânica e, portanto, pulsante. Compreender o processo de edificação desta Abordagem está, portanto, intimamente vinculado à trajetória epistemologicamente teórica/empírica que a professora Ana Mae Barbosa constitui em sua vida com a arte e o seu ensino.

Assim, a Abordagem Triangular, criada na trajetória epistemológica traçada pela professora Ana Mae Barbosa, em diálogo "[...] com o discurso pós-moderno global e o processo consciente da diferença cultural entre as nações [...]" (BARBOSA, 1998, p. 33), possui em sua gênese epistemológica, um caráter intrínseco de interação com outras abordagens do ensino de artes. 
Neste âmbito, dado seu caráter de/para uma proposição de ensino pela arte genuinamente contextual, ascende na Abordagem Triangular a particularidade de se contribuir para o fortalecimento das acepções contextuais na mediação das artes e seu ensino em suas diferentes esferas de ensino, nas diversas áreas de conhecimento.

Neste paradigma, com características marcantes da educadora que é e sempre nos ensina a ser, a professora Ana Mae, de modo generoso, acolhe nossas paixões e com profundo apreço por viagens em territórios desconhecidos lança seu olhar perspicaz e visionário, abrindo-nos a possibilidade de navegarmos na cibercultura para realizar a pesquisa. Quando concebemos, sob sua orientação, em minha tese de doutoramento a e-Arte/Educação ${ }^{1}$ e deste modo, analisamos as peculiaridades intrínsecas da cultura digital (a metalinguagem), sistematizamos o Sistema Triangular Digital.

Parafraseando o conceito da professora Ana Mae Barbosa e inserindo-o no universo da sociedade em rede, arte/educação intermidiática ou e-arte/educação é a mediação entre arte intermidiática (e/ou arte mista ${ }^{2}$ ) e público e ensino da arte intermidiático, que integra seus inputs e outputs, constituindo uma interface entre o universo tradicional e o universo em rede, quer seja no ensino formal ou informal.

Denominamos a abordagem e-arte/educativa ora proposta de Sistema Triangular Intermidiático, através do qual se sistematiza uma abordagem da educação digital inclusiva, por meio da educação intermidiática crítica. O Sistema Triangular Intermidiático é uma proposição derivativa da Proposta Triangular.

O Sistema Triangular Intermidiático está alicerçado nos fundamentos teóricos e conceituais da Abordagem Triangular, a qual foi concebida e sistematizada pela professora Ana Mae Barbosa, no âmbito da filosofia existencialista (ORTEGA Y

\footnotetext{
1 A tese de doutorado reverberou na publicação de dois livros intitulado, respectivamente: eArte/Educação: educação digital crítica. São Paulo: Annablume, 2012 e Técnica e tecnologia: a indústria ideológica massiva. São Paulo: Annablume, 2012.

2 Compreendemos por arte mista a arte composta por material digital e/ou não-digital.
} 
GASSET, 1963) e sob os auspícios do sistema não-linear da física social (BAUMAN, 2000; URRY, 2005).

A terminologia intermidiático informa a especificidade epistemológica, delimitação vértice que qualifica o campo do Sistema Triangular Intermidiático em relação à Abordagem Triangular. Esta derivação digital poderá dar maior subsídio arte/educativo aos desdobramentos contemporâneos da multimídia/intermídia como ambiente comunicacional simbólico e, assim, das manifestações das artes multi/intermidiáticas, no contexto da metalinguagem sob o advento da cultura digital.

O Sistema Triangular Digital e/ou Sistema e-Triangular: uma proposição eArte/Educativa pertence ao território de acontecimento de um novo estado da mente humana. Esse novo estado mental se estabelece com a metalinguagem: a mente digital, cuja preocupação essencial, neste sistema derivativo da Abordagem Triangular, é o desenvolvimento da consciência digital crítica.

\section{Metalinguagem: o novo estado da mente humana}

Compreende-se por meios de comunicação interligados a "[...] multimídia como ambiente simbólico [...]", pois, a partir da segunda metade da década de 90, "[...] um novo sistema de comunicação eletrônica começou a ser formado a partir da fusão da mídia de massa personalizada globalizada com a comunicação mediada por computadores" (CASTELLS, 1999, p. 387). Este novo sistema "[...] é caracterizado pela integração de diferentes veículos de comunicação e seu potencial interativo [...]" (CASTELLS, 1999, p. 387). Deste modo, multimídia, como o novo sistema foi chamado, amplia o espectro da comunicação, estabelecendo, portanto, um novo estado da mente humana, colocando-se no âmbito da tecnologia conceitual.

Assim, a multimídia (múltiplas mídias) ou intermídia (interconexão entre mídias), pela natureza do ambiente simbólico em que se insere na vida humana, "[...] estende o âmbito da comunicação eletrônica para todo o domínio da vida: de casa a trabalho, de escolas a hospitais, de entretenimento a viagens [...]" (CASTELLS, 1999, p. 392). Este fato, que é marcado pelo processo histórico e cultural da humanidade, é 
comparado por Castells ao advento do alfabeto na Grécia, em 700 a.C., que marcou um novo estado da mente humana.

Neste contexto, segundo os principais estudiosos clássicos, o alfabeto "[...] constituiu a base para o desenvolvimento da filosofia ocidental e da ciência como a conhecemos hoje. " (CASTELLS, 1999, p. 352), inserindo-se como uma tecnologia conceitual que tornou possível "[...] o preenchimento da lacuna entre o discurso oral e o escrito, com isso separando o que é falado de quem fala e possibilitando o discurso conceitual. " (CASTELLS, 1999, p. 353). Isto continuou até a sociedade alcançar, num longo processo evolutivo, um novo estado da mente, denominado "mente alfabética", originando uma nova qualidade da comunicação, como salienta Castells:

Esse momento histórico foi preparado ao longo de aproximadamente três mil anos de evolução da tradição oral e da comunicação não-alfabética até a sociedade grega alcançar o que Havelock chama de um novo estado da mente, "a mente alfabética", que originou a transformação qualitativa da comunicação humana (CASTELLS, 1999, p. 353).

O alfabeto não integra, entretanto, o discurso escrito do sistema audiovisual composto por imagens e sons, essenciais para a plena expressão e percepção humana. Assim, ao estabelecer "[...] a hierarquia social entre a cultura alfabetizada e a expressão audiovisual [...]", originou a relegação das imagens e sons pelo discurso escrito, cuja expressão audiovisual se restringiu às artes, uma vez que o "[...] preço pago pela adoção da prática humana do discurso escrito foi relegar o mundo dos sons e imagens aos bastidores das artes, que lidam com o domínio privado das emoções e com o mundo público da liturgia." (CASTELLS, 1999, p. 353). Deste modo, a imagem e o som são tidos como um sistema audiovisual de símbolos e percepções, sendo compreendidos, entretanto, como forma de expressão, mas não como cultura.

Com o advento do rádio e da TV no século XX, contudo, a cultura audiovisual "[...] teve sua revanche histórica [...]", "[...] superando a influência da comunicação escrita nos corações e almas da maioria das pessoas [...]" (CASTELLS, 1999, p. 353) - mas estando ainda imagem e som em dicotomia com a cultura alfabética.

Alguns especialistas, no afã de prever "a emergência de um novo veículo" que pudesse integrar os diferentes domínios da mente, como uma espécie de "telefone 
que escreve" através da Comunicação Mediada por Computador (CMC), apontam o correio eletrônico como possibilidade de misturar o discurso textual com o discurso oral.

A integração dos meios de comunicação presentes na sociedade em rede se apresenta, porém, com a interconexão entre o discurso textual, oral e audiovisual, perfazendo fortes mudanças paradigmáticas no espírito humano, que "[...] reúne suas dimensões em uma nova interação entre os dois lados do cérebro, máquinas e contextos sociais. " (CASTELLS, 1999, p. 354). A interação crescente entre mentes e máquinas, inclusive a máquina de DNA, está anulando o que Bruce Mazlish chama de a "quarta descontinuidade" (aquela entre seres humanos e máquinas), "[...] alterando fundamentalmente o modo pelo qual nascemos, vivemos, aprendemos, trabalhamos, produzimos, consumimos, sonhamos, lutamos ou morremos. (CASTELLS, 1999, p. 52). Compõem-se, então, novas formas de relações, bem como um novo estado da mente - a metalinguagem, que está proporcionando a infraestrutura mental para a comunicação integrada em um tempo escolhido (real ou atrasado), constituindo, assim, novo conceito de comunicação e, portanto, de cultura da humanidade. Nas palavras de Castells:

Uma transformação tecnológica de dimensões históricas similares está ocorrendo 2.700 anos depois, ou seja, a integração de vários modos de comunicação em uma rede interativa. Ou, em outras palavras, a formação do Supertexto e uma Metalinguagem que, pela primeira vez na história, integra no mesmo sistema as modalidades escrita, oral e audiovisual de comunicação humana (CASTELLS, 1999, p. 354).

Portanto,

A integração potencial de texto, imagens e sons no mesmo sistema interagindo a partir de pontos múltiplos, no tempo escolhido (real ou atrasado) em uma rede global, em condições de acesso aberto e de preço acessível muda de forma fundamental o caráter da comunicação. E a comunicação, decididamente, molda a cultura porque, como afirma Postman "nós não vemos... a realidade... como ela é, mas como são nossas linguagens. $E$ nossas linguagens são nossas mídias. Nossas mídias são nossas metáforas. Nossas metáforas criam o conteúdo de nossa cultura". Como a cultura é mediada e determinada pela comunicação, as próprias culturas, isto é, nossos sistemas de crenças e códigos historicamente produzidos são transformados de maneira fundamental pelo novo sistema tecnológico e o serão ainda mais com o passar do tempo (CASTELLS, 1999, p. 354). 
A interconexão entre os meios de comunicação digitais presentes na sociedade em rede propõe uma nova condição à mente humana - a mente metalinguística -, ao disponibilizar uma nova forma de comunicação. Nesta, o discurso escrito, até então reservado à cultura alfabética, integra-se ao discurso audiovisual e ao oral, preenchendo a lacuna entre estas três formas de discurso.

\section{Vivências pela internet: Realidade virtual ou virtualidade real?}

O ambiente digital constitui o suporte e o meio desta interação comunicacional, inserindo a sociedade num novo ambiente simbólico, em que se enlaça o virtual e o real. Ou seja, o que se caracteriza especificamente no contexto histórico está "[...] organizado pela integração eletrônica de todos os modos de comunicação, do tipográfico ao sensorial, não é a indução à realidade virtual, mas a construção da virtualidade real." (CASTELLS, 1999, p. 395).

Castells, a partir do Oxford Dictionary of Current English traz os conceitos "[...] virtual: que existe na prática, embora não estrita ou nominalmente [...]", e "[...] real: que existe de fato [...]", ao engajar a concepção semântica atribuída à terminologia virtual, com o conceito da realidade à experiência vivida, cuja prática da vida transborda para além das rigorosas definições semânticas, enaltece o caráter polissêmico das variações culturais do significado das mensagens:

[...] a realidade, como é vivida, sempre foi virtual porque sempre é percebida por intermédio de símbolos formadores da prática com algum sentido escapa à sua rigorosa definição semântica. É exatamente esta capacidade que todas as formas de linguagem têm de codificar a ambiguidade e dar abertura a uma diversidade de interpretações que torna as expressões culturais distintas do raciocínio formal/lógico/matemático. É por meio do caráter polissêmico de nossos discursos que a complexidade e até mesmo a qualidade contraditória das mensagens do cérebro humano se manifestam. Essa gama de variações culturais do significado das mensagens é o que possibilita nossa interação mútua em uma multiplicidade de dimensões, algumas explícitas, outras implícitas (CASTELLS, 1999, p. 395).

E conclui:

Portanto, quando os críticos da mídia eletrônica argumentam que o novo ambiente simbólico não representa "realidade", eles implicitamente referemse a uma absurda idéia primitiva de experiência real "não-codificada" que nunca existiu. Todas as realidades são comunicadas por intermédio de símbolos. E na comunicação interativa humana, independentemente do meio, todos os símbolos são, de certa forma, deslocados em relação ao sentido 
semântico que lhes são atribuídos. De certo modo, toda realidade é percebida de maneira virtual (CASTELLS, 1999, p. 395).

Mas o que é um sistema de comunicação que, ao contrário da experiência histórica anterior, gera virtualidade real?

É um sistema em que a própria realidade (ou seja, a experiência simbólica/material das pessoas) é inteiramente captada, totalmente imersa em uma composição de imagens virtuais no mundo do faz-de-conta, no qual as aparências não apenas se encontram na tela comunicadora da experiência, mas se transformam na experiência (CASTELLS, 1999, p. 395).

Deste modo, os meios de comunicação interligados compõem um novo paradigma cultural, o qual estabelece um novo estado da mente. Raymond Barglow, sob a égide da psicanálise social, aponta o fato paradoxal de que, embora aumente a capacidade humana de organização e integração, ao mesmo tempo os sistemas de informação e a formação de redes subvertem o conceito ocidental tradicional de um sujeito separado, independente. Em resumo, a tecnologia está ajudando a desfazer a visão do mundo por ela promovida no passado (BARGLOW, 1999 apud CASTELLS, 1999, p. 39-40).

Barglow apresenta, assim, uma comparação fascinante entre os sonhos clássicos relatados nos escritos de Freud e os sonhos de seus pacientes no ambiente de alta tecnologia na São Francisco dos anos 90:

\footnotetext{
Imagem de uma cabeça... e suspenso atrás dela há um teclado de computador... sou eu essa cabeça programada! Esse sentimento de solidão absoluta é novo em comparação à representação clássica freudiana: "os sonhadores... expressam um sentimento de solidão experimentado como existencial e inevitável, inerente à estrutura do mundo..." Totalmente isolado, - ser sente-se irrecuperavelmente perdido. Daí a busca por nova conectividade em identidade partilhada, reconstruída (FORBES apud CASTELLS, 1999, p. 40).
}

Sabemos das múltiplas interpretações que se pode atribuir aos sonhos; embora as interpretações não sejam objeto de nosso estudo, como a médica psiquiatra e psicanalista Cléo Lichtenstein Luz nos adverte, para Freud o sonho é a estrada em linha reta do inconsciente.

Este sonho relatado é relevante porque denuncia a presença das tecnologias contemporâneas através das comunicações computacionais como arcabouço do 
homem contemporâneo, que expressa seus sentimentos por meio dos símbolos icônicos que compõem a cultura digital. Este sonho que abarca imagem/símbolo/ícone presentes nos códigos computacionais denuncia que a cultura digital está muito mais impregnada em nossas mentes do que nossa consciência pode supor:

No novo sistema de mídia, nos sistemas de telecomunicações que se alteram rapidamente, nas redes de interação já formadas na Internet, na imaginação das pessoas, nas políticas dos governos e nas pranchetas dos escritórios das empresas. O surgimento de um novo sistema eletrônico de comunicação caracterizado pelo alcance global, integração de todos os meios de comunicação e interatividade potencial está mudando para sempre nossa cultura (CASTELLS, 1999, p. 354).

Uma das características, se não a mais importante, da intermídia é sua capacidade de captar a maioria das expressões no âmbito de sua diversidade social/cultural/tecnológica. Seu ponto marcante é o fim da separação e divisão entre as mídias audiovisuais e impressas e a oralidade, bem como o fim da separação entre cultura popular e erudita, entretenimento e informação. Assim, viabiliza a interação entre estes códigos comunicacionais num único universo digital interativo, constituindo um novo ambiente simbólico, o qual torna a virtualidade uma realidade expressiva que liga as manifestações, contidas em nossa mente comunicativa, em todos os seus tempos e espaços, transformando a virtualidade em um sistema comunicacional e, portanto real. Como adverte Castells:

Todas as expressões culturais, da pior à melhor, da mais elitista à mais popular, vêm juntas nesse universo digital que liga, em um supertexto histórico gigantesco, as manifestações passadas, presentes e futuras da mente comunicativa. Com isso, elas constroem um novo ambiente simbólico. Fazem da virtualidade nossa realidade (CASTELLS, 1999, p. 354).

Portanto, continua,

O tempo é apagado no novo sistema de comunicação, já que passado, presente e futuro podem ser programados para interagir entre si na mesma mensagem. $O$ espaço de fluxos e o tempo intemporal são as bases principais de uma nova cultura, que transcende e inclui a diversidade dos sistemas de representação historicamente transmitidos: a cultura da virtualidade real, onde o faz-de-conta vai se tornando realidade (CASTELLS, 1999, p. 397-398).

Ou seja, a cultura digital se constitui em uma rede de informações que, por meio de rotas escolhidas, poderá levar a pessoa a diferentes formulações. Para cada caminho traçado, podem haver resultados diferentes. Verdades que eram absolutas 
e, de certo modo, universais, agora são relativizadas, de acordo com o contexto que vai se amalgamando no percurso, instituindo o contexto como elemento significante e significativo neste meio - o contexto como elemento epistemológico.

O contexto é elemento fundamental para determinar a rota de significados e valores que construiremos em uma caminhada virtualmente empírica em nossas vidas, por isto mesmo em nossas mentes. Pela sua natureza estrutural sistêmica e, portanto, complexa, que subverte a relação entre tempo e espaço, sob os auspícios do conceito da modernidade líquida do sociólogo Zygmunt Bauman (2000) - por isto é um sistema não-linear -, a fluidez líquida do contexto transcende e se contrapõe à concepção da verdade única, inquestionável, de sistemas lineares presentes na física clássica.

\section{Rotas pela internet: Vulnerabilidade ou autogovernança}

Há quase três décadas, ascende em nossos hábitos e costumes um outro modo de comunicação e expressão, estabelecendo um paradigma digital que modifica nossa maneira de pensar e interagir uns com os outros de modo tão potente que modifica singularmente a qualidade estética de nossas práticas digitais de consumo. Assim, se faz imperativo que as políticas educacionais bem como as ações pedagógicas estejam consoantes à cultura digital em prol da formação autogovernativa de nossos alunos e alunas para se tornarem pessoas mais preparadas em seus mergulhos digitais. Educar para a criticidade digital é proteger. Precisamos desenvolver a consciência crítica de nossos alunos e alunas, desde a sua mais tenra idade, para serem capazes de navegar com autogovernança sem caírem em links que são verdadeiras armadilhas à vida, à pessoa. Há uma estreita diferença entre cair e escolher sentar.

É imperativo compreender que tecnologia não é coisa do futuro. A educação básica brasileira necessita acompanhar o tempo cibercultural dos nossos estudantes no tempo do presente, para assim não colocar para o futuro aquilo que há décadas já não é mais novidade acerca dos nossos hábitos e costumes na internet. Se o tempo da tecnocultura sempre estiver no tempo do futuro, este tempo sempre será inatingível 
e deste modo vamos presenciando a dura realidade que se assiste ainda em muitos lares e das escolas brasileiras: a segregação da cultura digital juvenil.

A cultura digital juvenil já desenha passado, presente e futuro. Quais pegadas em prol da formação da mente digital crítica a educação cibercultural de fato imprimiu na vida destes bilhões de consumidores digitais, efetivamente? E neste impasse entre segregar ou promover uma educação que não contemple a formação plena - porque libertária e por assim dizer que estabelece a criticidade digital, temos nos deparado ou com a educação digital tecnicista e/ou o e-laissez-faire ${ }^{3}$, assim questionamos: quais os hábitos e costumes vem sendo impressos na vida desses jovens que estão navegando por mais de 8 horas ao longo do dia na internet? Suas mentes digitais estão à disposição de quais saberes promovidos pela indústria cultural massiva? $\mathrm{Na}$ ausência do desenvolvimento pleno da consciência digital crítica destes internautas, a quais rotas que eles se destinam? Como Adverte Paulo Freire (2005), em seu livro Educação como prática para a liberdade, somente a educação promove a consciência crítica. A autogovernança não é fruto do acaso.

Neste impasse, que compreendo no paradigma da [ir]responsabilidade formativa de nossos jovens, identificamos educadores e sociedade que compreendem equivocadamente, que por terem seus filhos em casa e/ou na escola fazendo uso das plataformas digitais têm seus jovens resguardados dos "perigos da vida", ao entenderem que os muros de casa e/ou da escola podem proteger seus filhos e alunos da "vida lá fora". Mas, se esquecem de que a internet é a porta aberta para um mundo sem fronteiras, onde é a capacidade de escolha que pode determinar os rumos pela internet. O desenvolvimento da consciência autogovernativa pode evitar que pessoas despreparadas sejam sugadas pelo universo do entretenimento fácil, imediato, que antecede o direito de escolha. É neste paradigma, contrário à educação digital crítica, em prol do desenvolvimento da consciência autogovernativa, que se impera a verticalidade da indústria cultural massiva.

3 Ou e-laissez-faire é uma versão eletrônica do laissez-faire.Laissez-faire é parte da expressão em língua francesa ("laissez-faire, laissez-aller, laissez-passer"), que significa literalmente "deixai fazer". É o mote do liberalismo clássico. Disponível em: <http://pt.wikipedia.org/wiki/Laissez-faire>, acesso em 10 out. 2008. 
Há que se postular para que professores e professoras curupiras digitais, com suas pegadas invertidas, promovam ações e-arte/educativas em prol da ressignificação da tecnofloresta podendo [trans]formar o perigo que circunda a internet no desenvolvimento da consciência digital crítica.

Vale ressaltar que o Curupira é um personagem lendário ${ }^{4}$, protetor da flora e da fauna brasileira, que o folclore brasileiro nos conta que, de modo peculiar, este menino com pés do avesso, faz pegadas para trás, enganando os caçadores e os que retiram as riquezas da natureza. E, como nos conta Ana Paula de Araújo, o Curupira, que era um dos deuses oriundo da Mitologia Tupi-Guarani ${ }^{5}$, é também chamado de pai ou de mãe da natureza.

Compreendo que a professora Ana Mae Barbosa, com pés invertidos calçada com a Abordagem Triangular, é uma Curupira em prol da arte/educação no Brasil. E por assim dizer, da e-arte/educação. Obrigada, Ana Mae! Obrigada.

\section{Referências}

BARBOSA, Ana Mae. Tópicos e utópicos. Belo Horizonte: C/Arte, 1998.

BAUMAN, Zygmunt. Modernidade líquida. Rio de Janeiro: Zahar, 2000.

CASTELLS, Manuel. A sociedade em rede. A era da informação: economia, sociedade e cultura. 2. ed. v. 1. São Paulo: Paz e Terra, 1999.

CUNHA, Fernanda Pereira da. E-arte/educação: educação digital crítica. São Paulo: Annablume, 2012. CUNHA, Fernanda Pereira da. Técnica e tecnologia: a indústria ideológica massiva. São Paulo: Editora Annablume, 2012.

FREIRE, Paulo. Educação como prática da liberdade. 28. ed. Rio de Janeiro: Paz e Terra, 2005.

ORTEGA Y GASSET, José. Meditação da técnica. Tradução e Prólogo de Luís Wahington Vita. Rio de Janeiro: Livro Ibero-Americano Limitada, 1963.

URRY, John. The complexity turn. Theory, Culture \& Society. SAGE, London, Thousand Oaks and New Delhi, v. 22, n. 5, p. 1-14, 2005.

4 Para maiores informações sobre a lenda do Curupira está disponível em: <http://cultura.culturamix.com/literatura/a-lenda-do-caipora-ou-curupira>, acesso em 10 fev. 2017.

5 Para conferir 0 artigo sobre Mitologia tupi na íntegra visite a página: <http://www.infoescola.com/mitologia/mitologia-tupi-guarani/>, acesso em 10 fev. 2017. 


\section{Fernanda Pereira da Cunha}

Possui graduação em Educação Artística - Licenciatura Plena pela Fundação Armando Álvares Penteado, mestrado em Artes pela Universidade de São Paulo e doutorado em Artes pela Universidade de São Paulo. Atualmente é Professora Adjunta da Escola de Música e Artes Cênicas da Universidade Federal de Goiás (EMAC/UFG). Tem experiência na área de Artes, atuando principalmente nos temas: Intermídia, Cultura Digital, e-Arte/Educação. Foi vice coordenadora do Programa de Pós-Graduação Stricto Sensu (mestrado e doutorado) Interdisciplinar em Performances Culturais (EMAC/UFG) (20142016). É professora do Programa de Pós-Graduação Stricto Sensu (mestrado) em Música (EMAC/UFG). É coordenadora do Curso de Especialização em Arte/Educação Intermidiática (EMAC/UFG).

E-mail: fernanda.pcunha@hotmail.com

Currículo: http://lattes.cnpq.br/8739909013018488

Recebido em 13 de março de 2017 Aceito em 18 de maio de 2017 